\title{
INVESTIGATION OF STRESS STATUS IN THE MICRO-SPACE OF SURFACE AND SUBSURFACE LAYERS
}

One of main issues when evaluating or analysing quality and functional properties of work-piece is identification of status of residual stress. Every treatment or machining process generates residual stress in the surface and subsurface layers of the material structure. The residual stress has a large influence on the functional properties of the components. The article is focused on the method of triaxial measurement of residual stress after machining the surface of sample by high feed milling technology. Significance of triaxial measuring is the capability of measuring in different angles so it is possible to acquire stress tensor containing normal and shear stress components acting in the spot of measuring, using a Cartesian coordinate system.

Keywords: X-ray diffractometry, residual stress, stress tensor, microstructure.

\section{Introduction}

Residual stresses are an integral part of manufactured workpieces, whether they are introduced deliberately, as a part of the design, as a by-product of a process carried out during the manufacturing process, or are present as the product of the component's service history. Residual stresses are additive with the stresses existing in the workpieces as a result of service loads [1 - 3].

Residual stresses can be formed below the machined surface only if there is a plastic deformation in the surface layer. The sense of residual stress (tension or pressure) depends on how the deformation occurred. This can be caused by the following factors: thermal phase transformation, thermal and plastic deformation, mechanical deformation [4 - 7].

The stress which can occur in closed systems can be classified according to various aspects. The stress can be tension $(+)$ or compression (-). Residual stresses can be characterized by the scale at which they exist within a material. Stresses that occur over long distances within a material are referred to as macro-stresses. Stresses that exist only locally (either between grains or inside a grain) are called micro-stresses. The total residual stress at a given location inside a material is the sum of all 3 types of stresses (Fig. 1) [8 - 10].

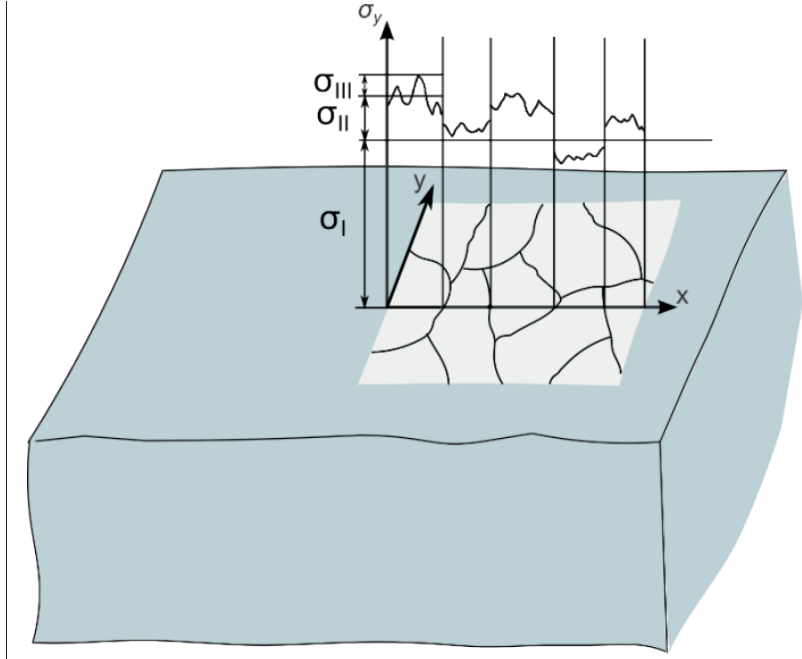

Fig. 1 Types of residual stress [8]

Type I Stresses (Fig. $1-\sigma_{\mathrm{I}}$ ): Macro-stresses occurring over distances that involve many grains within a material.

Type II Stresses (Fig. $1-\sigma_{\text {II }}$ ): Micro-stresses caused by differences in the microstructure of a material and occur over distances comparable to the size of the grain in the material. They can occur in single-phase materials due to the anisotropic

\footnotetext{
* ${ }^{1}$ Andrej Czan, ${ }^{1}$ Michal Sajgalik, ${ }^{1}$ Lucia Zauskova, ${ }^{2}$ Robert Cep, ${ }^{3}$ Zdenka Rysava, ${ }^{4}$ Vitor Luiz Sordi

${ }^{1}$ Department of Machining and Manufacturing Technology, Faculty of Mechanical Engineering, University of Zilina, Slovakia

${ }^{2}$ Department of Machining and Assembly, Faculty of Mechanical Engineering, VSB -Technical University of Ostrava, Czech Republic

${ }^{3}$ Departement of Industrial Engineering, University of Padua, Italy

${ }^{4}$ Departamento de Engenharia de Materiais, Brasil

E-mail: andrej.czan@fstroj.uniza.sk
} 
behaviour of individual grains, or can occur in multi-phase material due to the presence of different phases.

Type III Stresses (Fig. $1-\sigma_{\mathrm{III}}$ ): Exist inside a grain as a result of crystal imperfections within the grain [5, 8 and 9].

There are three mechanisms of mechanical deformations (shown in Fig. 2). In the first model, the residual stress is caused by a volume change (Fig. 2(a)). If the change in phase causes a decrease in volume, as shown, the surface layer wants to contract but the underlying bulk material will resist this. The result is that the surface layer is under tension. This example produces a tensile residual stress. If the phase transformation causes an increase in volume, the residual stress will be compressive. This is the case with the conventional heat treatment of steel. It also applies to nitriding but the volume increase is caused by diffusion. In the second model, the unit event heat causes expansion of the surface layer and this expansion is relieved (whilst the heating is maintained) by plastic flow, which is restricted to the surface layer. When the heat is removed, the surface layer contracts, resulting in a tensile residual stress (Fig. 2 (b)). In the third model, the residual stress is compressive because the surface layer is compacted by some form of mechanical action (Fig. 2 (c)). There are no heating effects. This applies to burnishing, peening and abrasive jet machining. Processes consisting of only chemical unit events will produce zero residual stress [6 - 8 and 10].

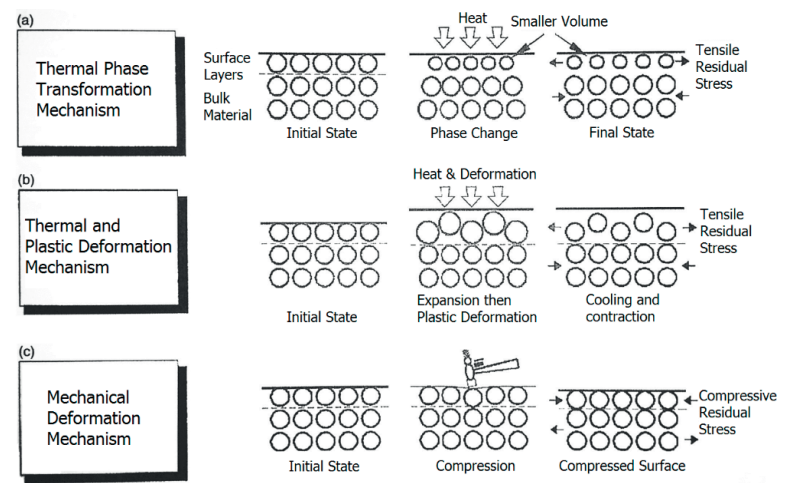

Fig. 2 Three residual stress models [3]

Obviously, to realize the benefits of understanding the residual stresses in parts and structures, tools are needed to measure them. Several techniques are available, with varying degrees of sophistication. Some of them are rather limited in their application, but one stands out as having widespread applications and being readily available $[9,11-12]$.

$\mathrm{X}$-ray diffraction is a specific method that can measure residual stress quantitatively in crystalline and semi-crystalline materials, which include virtually all metals and their alloys, and most ceramic materials [1, 9 and 13].

Its advantage is the non-destructive character of measurement and it observes only the elastic deformation, which is proportional to the residual stress size. The principle of X-ray diffractometry is based on the influence of residual stress in the crystallographic lattice and distance of its planes (d), which is measured. As long as the stress is zero, the distance of crystallographic planes only depends on the material properties. These distances can vary by the influence of the residual stress. Any change in the crystallographic planes distance $d$ results in the corresponding diffraction angle. The incident X-ray beam penetrates the surface layers of the material, where depending on the crystallographic planes distance it diffracts to the diffraction cone recorded on the detectors $[2,14-16]$.

\section{Experiment conditions}

Experiments were performed on the sample from material 17240 (X5CrNi18-10) with dimensions of $150 \times 30 \times 30 \mathrm{~mm}$. Chemical properties of material are listed in Table 1.

Chemical composition of sample material (wt.\%) Table 1

\begin{tabular}{|c|c|c|c|c|c|c|}
\hline C & Mn & Si max & Cr max & Ni max & P max & S max \\
\hline 0.07 & 2 & 0.7 & 20 & 11.5 & 0.045 & 0.03 \\
\hline
\end{tabular}

A sample for the experiment was machined by technology of high feed milling with cutting parameters $a_{p}=0.5 \mathrm{~mm}, v_{c}=150 \mathrm{~m}$. $\min ^{-1}, f_{z}=1 \mathrm{~mm}$. Surface of the sample was degreased before the measurements. For residual stress detection in the material an X-ray tube with $\mathrm{Cr} \mathrm{K} \alpha$ anode was used. The measurements were performed with $\emptyset 1 \mathrm{~mm}$ collimator. The aim of the experiments was to compare the detection of residual stresses by methods of axial measurement and surface mapping, with the method of triaxial measurement.

The measuring of residual stress and was performed with Proto XRD diffractometer (Fig. 3), using WINXRD 2.0 software.

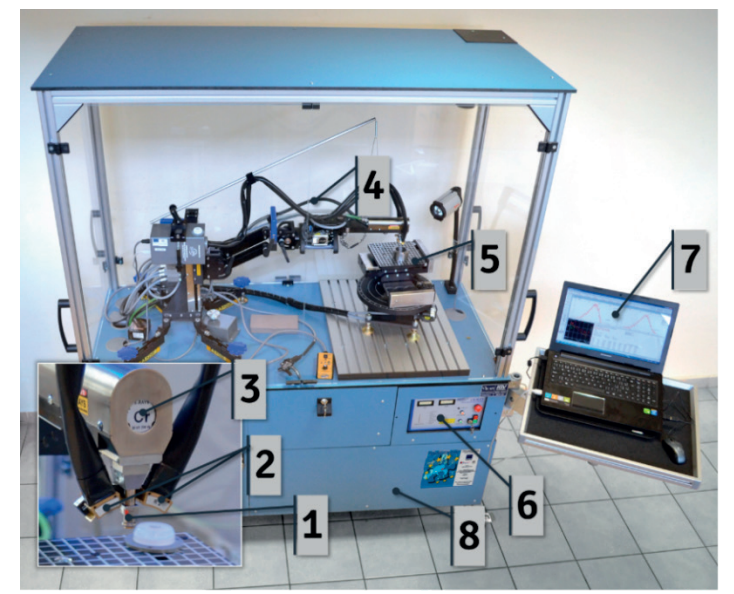

Fig 3. X-ray diffraction residual stress measurement system (stationary: 1 - collimator; 2 - two detectors for diffraction cone; 3 - X-ray tube; 4 - Cobralink ${ }^{\circledR}$ flexible arm; 5 - positioning and rotary table; 6 - control unit; 7 - PC with software; 8 - laboratory stand 

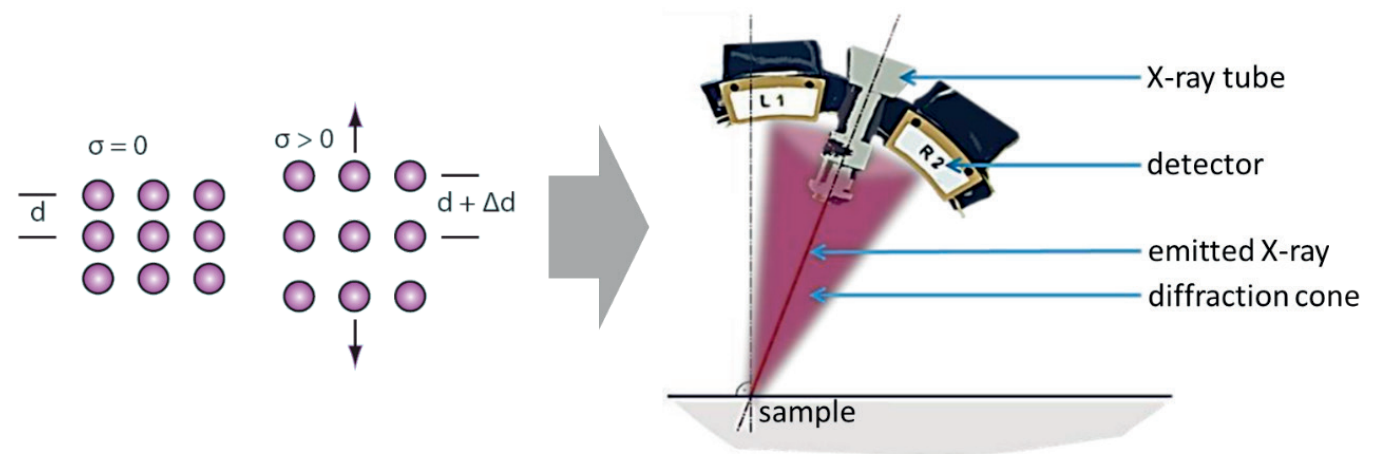

Fig. 4 Principle of measuring of residual stress by X-ray diffractometry based on Brag's Law

From the theory of elasticity the relationship between residual stress $(\sigma)$ and strain $(\varepsilon)$ on the sample surface under plane stress is given by the Bragg equation, $\lambda=2 d \sin \theta$, relating incident $\mathrm{X}$-ray wavelength $(\lambda)$, lattice inter-planar spacing $(d)$ and diffraction angle $(\theta)$ (Fig. 4).The direction of maximum residual stress, which can be tensile or compressive, is assumed to occur in the cutting or grinding direction during most machining operations. But maximum stress often occurs at significant angles to the cutting direction. Furthermore, the residual stress distributions produced by many cutting operations, such as turning, may be highly eccentric, producing a highly tensile maximum stress and a highly compressive minimum stress.

\section{Experimental results}

\subsection{Axial depth measurement}

When using axial residual stress measurement, the measured area corresponds to the size of collimator ( $1 \mathrm{~mm}$ diameter). Measurements were performed at three different points in total. After the measuring of residual stress, electrochemical polishing was applied, because X-ray beam penetrates to a depth of only few microns. Measurements were then repeated. The thickness of etched layers was determined on the $20 \mu \mathrm{m}$. The surface was etched 10 times and we reached a depth of $200 \mu \mathrm{m}$ under the machined surface. Values of normal and sheer stresses generated by the software were averaged and then plotted into a residual stress graph depending on the depth in the material (Fig. 5).

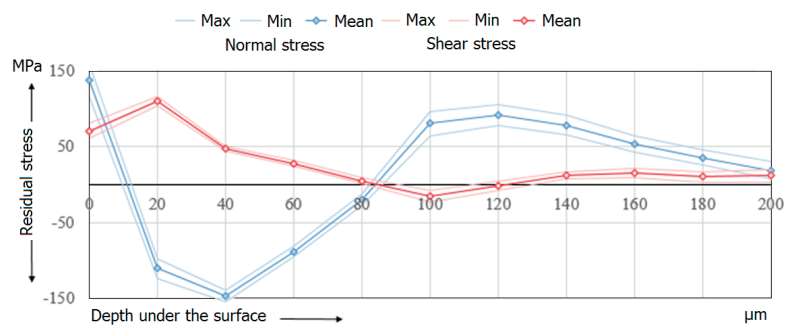

Fig. 5 Residual stress depending on the depth under the surface
The tensile shear stress with value of $137 \mathrm{MPa}$ was measured in the surface layer. In the depth of approximately $11 \mu \mathrm{m}$ the character of normal residual stress changed from tensile to compressive. The stress in etched layers was then growing to a depth of $40 \mu \mathrm{m}$, where it reached a maximum value of $147 \mathrm{MPa}$. In the depth of approximately $85 \mu \mathrm{m}$ the normal stress reached tensile character again. The value of $92 \mathrm{MPa}$ was reached in a depth of $120 \mu \mathrm{m}$. The shear stress in the surface layer had the tensile character with a value of $70 \mathrm{MPa}$. At a depth of $20 \mu \mathrm{m}$ the maximum value of $110 \mathrm{MPa}$ was detected. In the following measured layers a continuous descent into compressive stress at a depth of $85 \mu \mathrm{m}$ was found. The maximum value of $15 \mathrm{MPa}$ of compressive character was reached at a depth of $100 \mu \mathrm{m}$ under the surface finish.

\subsection{Square mapping measurement}

Surface mapping is possible to provide by an automated table with $\mathrm{X}$ and $\mathrm{Y}$ axes. It consists of individual axial measurements covering a determined area. The experiment methodology of monitoring the stress condition in the surface and subsurface layers was performed at the $10 \times 10 \mathrm{~mm}$ area of the machined surface with $2 \mathrm{~mm}$ rasterization in the $\mathrm{X}$ direction $\left(v_{f}\right)$ and $\mathrm{Y}$ direction $\left(v_{c}\right)$. On the basis of the measured values the graphic correlation of residual stresses was constructed in individual directions of an acting cutting wedge. The results of individual experimental measurements were processed into $2 \mathrm{D}$ and $3 \mathrm{D}$ graphs to further show the effect of cutting parameters on the formation of residual stresses and thus to confirm the recent theoretical and practical knowledge of the residual stresses and their formation, of which the functional properties of machined surfaces depend. 


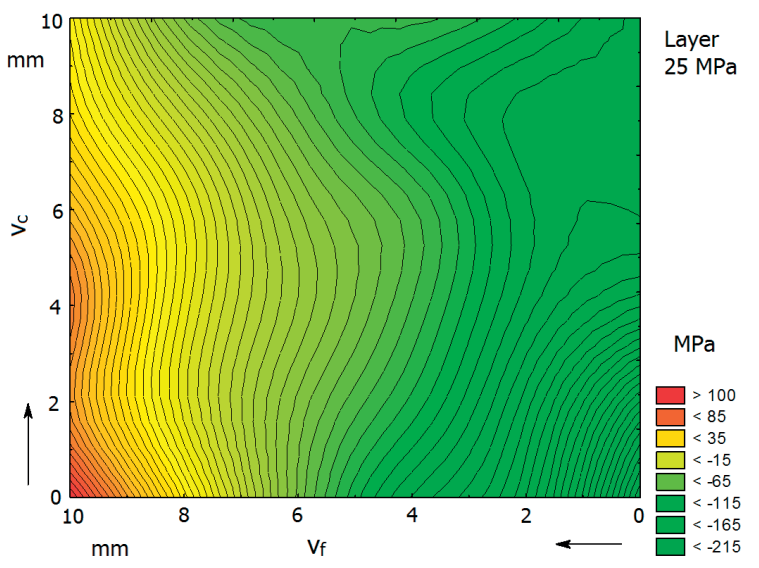

Fig. $62 D$ visualization of the normal residual stress

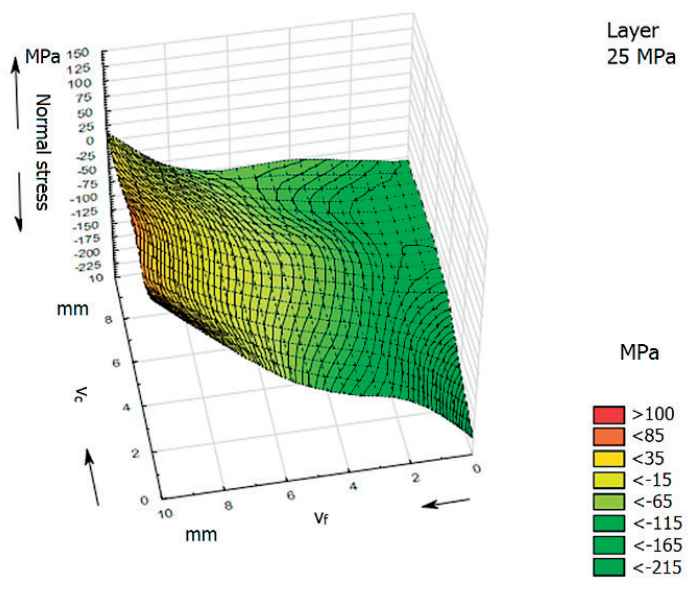

Fig. $73 D$ visualization of the normal residual stress

By observing the normal stress in Fig. 6, the effects of feed and cutting speed on machined surface were perceived, where areas with presence of compressive normal stress within $200 \mathrm{MPa}$ with gradual transition to a tensile stress of about $100 \mathrm{MPa}$ in the direction of the feed speed were identified. This phenomenon was not observed in the direction of cutting speed. The methodology of experimental solutions proves that it is important to observe the local residual stress states in the local rasterization, where it is possible to observe the extreme of statistical representation function, which is strongly visible in Fig. 7. In the representation the layering can be seen, and also the steepness of the function of monitored area with layering of $25 \mathrm{MPa}$. Overall, it can be stated that under given conditions there is a radical change in the orientation of normal stress on the surface from compressive to tensile character.

\subsection{Triaxial measurement}

The significance of triaxial residual stress measurement is measuring at various angles $\phi$, so it is possible to obtain a stress tensor containing normal and shear stress components acting at the point of measurement. If the measurements for three directions in the sample are recorded, (generally $\phi=0^{\circ}, 45^{\circ}$, $90^{\circ}$ ), then the full stress tensor can be calculated, comprising the normal stress for each of the measured directions, and the shear stresses also. For calculation of the stress tensor, it is generally assumed that the stress normal to the specimen surface, $\sigma_{33}$, is zero. There can be no stress normal to a free surface in equilibrium. However, a stress can be maintained in this surfacenormal direction at some depth below the surface. Hence for some deeply penetrating measurements (tens of microns), it is possible that a non-zero value of stress could be present. In this case, calculation of the stress tensor requires knowledge of the stress-free lattice parameter $d_{0}$ for the examined material [12 and 13].

Measured values of normal and shear stress at $\varphi$ angles Table 2

\begin{tabular}{ccc}
\hline$\varphi\left[{ }^{\circ}\right]$ & Normal stress [MPa] & Shear stress [MPa] \\
\hline $\mathbf{0}$ & $436.3 \pm 13.1$ & $21.3 \pm 6.6$ \\
45 & $365.9 \pm 11.6$ & $34.6 \pm 5.9$ \\
$\mathbf{9 0}$ & $209.5 \pm 15.6$ & $26.9 \pm 7.9$ \\
\hline
\end{tabular}

Triaxial detection of residual stresses consisted of measurements at three $\varphi$ angles, which are listed in Table 2 together with measured normal and shear stresses. The stress tensor with corresponding error was then created from the measured values (Eq. (1)). The software of measuring device generates stress tensor with the condition that the value of $\sigma_{33}$ is zero. $d_{0}$ calculated by the software had a value of 1.171672 . The value $\mathrm{d}_{0}$ of etalon had during calibration an initial value of 1.1702087. Normal stress $\sigma_{11}$ in the feed direction had a value of 474.09 MPa. Normal stress $\sigma_{22}$ had a lesser value of 200.85 MPa, due to the impact of tool axis movement.

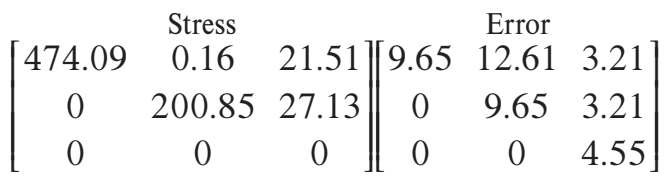

\section{Discussion and conclusion}

The aim of article was to compare the various methods of residual stress analysis after high feed milling. The simple axial measurement proved monitoring of residual stress states in very thin layers, pushing the limits of layer analyzing right from the surface. By implementing the electrochemical polishing it is 
possible to examine the residual stresses, their character and continuation into depth of the material, making it possible to obtain confirming or refuting information and knowledge of residual stress across the cross-section from the surface to the depth of the examined sample. An interesting challenge was measuring the area of $10 \times 10 \mathrm{~mm}$ to ensure monitoring of the impact of cutting wedge on the development of residual stress in the $\mathrm{X}$ direction of feed speed and the $\mathrm{Y}$ direction of cutting speed. The applied method offers the possibility to acquire the knowledge to build theoretical definitions of residual stress formation in the direction of cutting wedge action. Subject of a new research is the method of triaxial measurement of residual stresses, which makes it possible to monitor residual stresses and their impact on the volume within a Cartesian coordinate system. The method can be used in closer examination of the impact of cutting tool on the residual stress formation in the material. The method offers many possible applications in order to verify and extent the theoretical knowledge in this topic, and will be further examined.

\section{Acknowledgements}

This article was funded by the University of Zilina project OPVav-2009/2.2/04-SORO number (26220220101) - "Intelligent system for non-destructive technologies on evaluation for the functional properties of components of X-ray diffraction."

\section{References}

[1] GANEV N., KRAUS I.: X-ray Diffraction Measurement of Residual Stresses. Material Structure, 9, 2, 2002.

[2] FITZPATRICK, M. E. et. al.: Determination of Residual Stresses by X-ray Diffraction. Measurement Good Practice No. 52. National Physical Laboratory: Teddingtoon, 2005.

[3] VASILKO, K., PILC, J.: New Technological Knowledge of the Rotary Turning Tool. J. Manufacturing Technology, 13, 4, 2013, 571575.

[4] KRAJCOVIC, M., BULEJ, V., SAPIETOVA, A., KURIC, I.: Intelligent Manufacturing Systems in Concept of Digital Factory. Communications - Scientific Letters of the University of Zilina, 15, 2, 2013, 77-87.

[5] GRZESIK, W.: Advanced Machining Processes of Metallic Materials: Theory, Modelling and Applications. Elsevier, 2008, 446.

[6] HOLESOVSKY, F., NOVAK M., LATTNER M., VYSLOUZIL, T.: Machining and its Influence to Surface Quality of Machine Parts. Precision Machining VII, 581, 2014, 354-359.

[7] BENO, J., MANKOVA, I., IZOL, P., VRABEL, M.: An Approach to the Evaluation of Multivariate Data during Ball End Milling Free-Form Surface Fragments. Measurement, 84, 2016, 7-20.

[8] STANCEKOVA, D., SEMCER, J., HOLUBJAK, J., DRBUL, M.: Machinability of Nano-Structured Biomaterials for Dental Implants. Communications - Scientific Letters of the University of Zilina, 16, 3A, 2014, 96-100.

[9] DRBUL, M., SAJGALIK, M., SEMCER, J., CZANOVA, T., PETRKOVSKA, L., CEPOVA, L.: Metrology and Quality of Surfaces

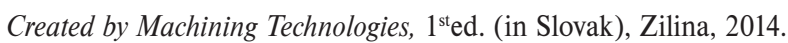

[10] SAGA, M., VASKO, M., KOPAS, P., JAKUBOVICOVA L.: Numerical Algorithm for Beam Residual Stress Identification. Communications - Scientific Letters of the University of Zilina, 16, 3A, 2014, 13 - 18.

[11] BREZINA, M., KUPCA, L.: Stress Corrosion Cracking of Austenitic Stainless Steel in a Nuclear Power Plant Environment. Environment Inducted Cracking of Materials. Department of Structural Analysis, VUJE Inc: Trnava, 2008, 431 - 436.

[12] MOHYLA, P., TOMCIK, P., BENES, L., HLAVATY, I.: Effect of Post-Welding Heat Treatment on Secondary Hardening of Welded Joints of Cr-Mo-v Steel. Metal Science and Heat Treatment, 53, 7-8, 2011, 374-378.

[13] MARTIKAN, P., DRBUL, M., HOLUBJAK, J., MRAZIK, J., JOCH, R.: The Issue of Determining the Geometric Position Deviation of the Threaded Holes. Advances in Science and Technology-Research J., 10, 32, 2016, 47-52.

[14] DUPLAKOVA, D., KNAPCIKOVA, M., HATALA, M., SZILAGYI, E.: Mathematical Modeling of Temperature Characteristics of RFID Tags with their Subsequent Application in Engineering Production. Tem Journal-Technology Education Management Informatics, 5, 2016, 411-416.

[15] PeTRU, J., ZlAMAL, T., CEP, R., STANCEKOVA, D., PAGAC, M., VORTEL, O.: Mechanisms of Cutting Insert Wear and their Influence on Cutting Ability of the Tool During Machining of Special Alloys. $3^{\text {rd }}$ intern. conference on Manufacturing Engineering and Technology for Manufacturing Growth, 2015, 36-40.

[16] CZAN, A., TILLOVA, E., SEMCER, J., PILC, J.: Surface and Subsurface Residual Stresses after Machining and their Analysis by X-ray Diffraction. Communications - Scientific Letters of the University of Zilina, 15, 2, 2013, 69-76. 